ORIGINAL ARTICLE

\title{
Respiratory infections in schoolchildren: co-morbidity and risk factors
}

\author{
G Karevold, E Kvestad, P Nafstad, K J Kværner
}

See end of article for authors' affiliations .......................

Correspondence to: Mrs G Karevold, Department of Otorhinolaryngology,

Akershus University Hospital, Sykehusveien 27 $\mathrm{N}-1478$ Lørenskog Norway; gunnhild@ karevold.no

Accepted 30 January 2006 Published Online First 7 February 2006
Aims: To assess co-morbidity and risk factors for otitis media, tonsillopharyngitis, and lower respiratory infections in school children.

Methods: Logistic regression analysis of co-morbidity and risk factors for airway infections in a population based sample of 10 year old children living in Oslo, Norway. Main outcome measures: otitis media, tonsillopharyngitis, and lower respiratory infections in past 12 months.

Results: Airway infections in 10 year old children were common, and significant co-morbidity was found between the various airway infections. Home dampness was a risk factor for all infections, adjusted odds ratios ranging from $1.2(95 \% \mathrm{Cl} 1.0$ to 1.5$)$ to $1.4(95 \% \mathrm{Cl} 1.1$ to 1.6$)$ for otitis media and tonsillopharyngitis respectively. Atopic disease was a constitutional risk factor, particularly strong for lower airway infections (adjusted odds ratio $2.4,95 \% \mathrm{Cl} 1.8$ to 3.1 ). African or Asian ethnicities were associated with the airway infections, adjusted odds ratios ranging from $1.2(95 \% \mathrm{Cl} 0.9$ to 1.7$)$ to $1.7(95 \% \mathrm{Cl} 1.2$ to 2.3).

Conclusions: Respiratory tract infections were common in 10 year old children. There was substantial comorbidity between upper and lower airway infections. Environmental and constitutional factors were identified and positively associated with the infections. Results support the hypothesis of 1957 that the whole respiratory tract is one unit.
B oth viral and bacterial agents have been proposed to play important roles in the development of childhood airway infections. ${ }^{1}$ Changes in the local and innate immunity of the pharyngeal space also influence upper respiratory infections. ${ }^{2}$ In 1957 upper respiratory disease was considered to play an important role in the aetiology of middle ear disease; the same report generalised that the whole respiratory tract should be seen as a unit liable to similar natural changes. ${ }^{3}$

The focus of otitis media research has so far been toddlers and preschool children. ${ }^{45}$ Less is known about occurrence and risk factors for otitis media in older children. Furthermore, population based prevalence estimates of tonsillopharyngeal infections are lacking. Mattila et al reported tonsillitis to occur in children of school age, based on operative rates. ${ }^{6}$ Other reports on tonsillitis have addressed specific bacterial agents or the effects of antibiotic treatment. $^{78}$ This is equally true for community acquired lower respiratory infections. ${ }^{9}$ Epidemiological research has found co-morbidity between upper airway infections, but whether there also is a concurrence between infections of the upper and lower airways has not been fully explored. ${ }^{10-12}$

To contribute to the present knowledge of childhood respiratory tract infections, our research aims were to study prevalence, and assess risk factors for infectious co-morbidity in otitis media, tonsillopharyngitis, and lower respiratory infections in 10 year old children.

\section{METHODS}

As part of the follow up of the Oslo Birth Cohort, ${ }^{13}$ a population based cross-sectional survey was conducted among 10 year old children. Children eligible were born in 1992, living in Oslo in 2001, with a registered valid mailing address $(\mathrm{n}=5125)$. The questionnaire was self-administered and focused on atopic disease and environmental exposures. The response rate was 66\%; 3406 parents returned the forms to the Norwegian Institute of Public Health. The study was approved by the Data Inspectorate of Norway and the Medical Research Ethics Committee.

The outcomes of interest were otitis media, tonsillopharyngitis, and lower respiratory infections during the previous 12 months. In the questionnaire the questions were formulated as follows: Has the child had any of the following infections-otitis media, tonsillopharyngitis, bronchitis, or pneumonia-in the past 12 months? If yes, how many episodes past year? Otitis media was defined as one or more episodes of ear infection; tonsillopharyngitis as having one or more episodes of throat infection. Lower respiratory infection was coded as having one or more episodes of bronchitis, pneumonia, or both.

Risk factors for infection were divided into environmental and constitutional factors.

Signs of home dampness, siblings, smoking by care providers, and maternal education were categorised as environmental determinants, whereas gender, atopic predisposition, and ethnic origin were constitutional determinants.

Home dampness was classified by signs of mould, water leakage in the house, spots of moisture on walls or ceiling, and dew on the windows during winter. The latter four variables were analysed separately and subsequently merged into a single variable representing home dampness. The sibling variable was dichotomised into no siblings and siblings. Smoking by care-providers was registered as mother smoking during pregnancy or during infancy, or any family member smoking indoors at present. The questions were merged into the variable care-givers' smoking. Maternal education was grouped as less than 12 years, 12-15 years, and more than 15 years of education. Childhood atopy was defined as physician diagnosed rhinoconjunctivitis, asthma, or both. Ethnic origin was derived from nationality of the parents. Children with one or both parents from African, Asian, and Caucasian countries were categorised as being African, Asian, and Caucasian, respectively. Caucasian was used as reference category. The 100 mixed ethnicity parents, 


\begin{tabular}{|c|c|c|c|c|}
\hline Characteristics & $\begin{array}{l}\text { Otitis media } \\
\mathrm{n}=470\end{array}$ & $\begin{array}{l}\text { Tonsillopharyngitis } \\
\mathrm{n}=737\end{array}$ & $\begin{array}{l}\text { Lower respiratory } \\
\text { infections } \\
n=275\end{array}$ & $\begin{array}{l}\text { Total study } \\
\text { population } \\
\mathrm{n}=3406\end{array}$ \\
\hline \multicolumn{5}{|l|}{ Gender } \\
\hline Female & 53.0 & 51.6 & 44.7 & 49.1 \\
\hline Male & 47.0 & 48.4 & 55.3 & 50.9 \\
\hline \multicolumn{5}{|l|}{ Atopic disease } \\
\hline Child & 26.8 & 26.3 & 41.6 & 21.6 \\
\hline Parents & 62.3 & 60.4 & 67.2 & 56.8 \\
\hline \multicolumn{5}{|l|}{ Siblings } \\
\hline Yes & 88.3 & 88.6 & 85.1 & 87.7 \\
\hline No & 11.7 & 11.4 & 14.9 & 12.3 \\
\hline \multicolumn{5}{|c|}{ Smoking by care-giver } \\
\hline Yes & 30.9 & 29.3 & 31.6 & 28.8 \\
\hline No & 69.1 & 70.7 & 68.4 & 71.2 \\
\hline \multicolumn{5}{|l|}{ Home dampness } \\
\hline Yes & 37.4 & 39.2 & 38.9 & 32.7 \\
\hline No & 62.6 & 60.8 & 61.1 & 67.3 \\
\hline \multicolumn{5}{|c|}{ Maternal education } \\
\hline$<12$ years & 44.7 & 44.1 & 44.0 & 42.9 \\
\hline $12-15$ years & 28.1 & 26.9 & 25.8 & 28.2 \\
\hline$>15$ years & 24.7 & 27.3 & 25.8 & 27.1 \\
\hline \multicolumn{5}{|l|}{ Parental ethnicity } \\
\hline Caucasian & 75.3 & 61.3 & 44.0 & 78.7 \\
\hline African & 8.3 & 8.8 & 9.5 & 6.4 \\
\hline Asian & 13.8 & 15.9 & 9.5 & 13.0 \\
\hline
\end{tabular}

all Caucasian and Asian, were included in the Asian ethnicity group. When odds ratios were estimated for the association between ethnicity and infections, analyses with and without the inclusion of the mixed Asian parents did not yield different results.

Prevalence measured disease occurrence in the study population. By logistic regression analysis the concurrence of the respiratory infections and associations with environmental and constitutional exposures were estimated as odds ratios (ORs) with 95\% confidence intervals (95\% CI). Multivariate logistic regression analysis was applied for adjustment of odds ratios.
Missing information was given a separate value and analyses were performed with and without the missing category. Both approaches gave consistent results, the difference in odds ratio being less than 0.1 . The results presented in this manuscript include strata of missing data. The statistical software package for social sciences version 12.0.1 for Windows (SPSS Inc., Chicago, IL) was used for all statistical analysis.

\section{RESULTS}

At least one episode of otitis media during the last 12 months was reported by $13.8 \% \quad(n=470)$ of the children.

Table 2 Associations between gender, child atopy, dampness, smoking, siblings, maternal education, parental ethnicity, and respiratory infections

\begin{tabular}{|c|c|c|c|c|c|c|}
\hline & \multicolumn{2}{|c|}{ Otitis media ( $n=470$ ) } & \multicolumn{2}{|c|}{ Tonsillopharyngitis ( $\mathrm{n}=737$ ) } & \multicolumn{2}{|c|}{$\begin{array}{l}\text { Lower respiratory tract infections } \\
(n=275)\end{array}$} \\
\hline & cOR & aOR & COR & aOR & COR & aOR \\
\hline \multicolumn{7}{|l|}{ Gender } \\
\hline Male & Ref. & Ref. & Ref. & Ref. & Ref. & Ref. \\
\hline Female & $1.2(1.0-1.5)$ & $1.2(1.0-1.5)$ & $1.1(1.0-1.3)$ & $1.2(1.0-1.4)$ & $0.8(0.6-1.1)$ & $0.9(0.7-1.1)$ \\
\hline \multicolumn{7}{|l|}{ Atopy } \\
\hline Non-atopic children & Ref. & Ref. & Ref. & Ref. & Ref. & Ref. \\
\hline Atopic children & $1.4(1.1-1.8)$ & $1.4(1.1-1.8)$ & $1.4(1.2-1.7)$ & $1.4(1.1-1.7)$ & $2.4(1.9-3.1)$ & $2.4(1.8-3.1)$ \\
\hline \multicolumn{7}{|l|}{ Home environment } \\
\hline No dampness & Ref. & Ref. & Ref. & Ref. & Ref. & Ref. \\
\hline Home dampness & $1.3(1.0-1.6)$ & $1.2(1.0-1.5)$ & $1.4(1.2-1.7)$ & $1.4(1.1-1.6)$ & $1.4(1.1-1.8)$ & $1.3(1.0-1.7)$ \\
\hline No smoking & Ref. & Ref. & Ref. & Ref. & Ref. & Ref. \\
\hline Smoking by care-giver & $1.1(0.9-1.4)$ & $1.2(0.9-1.5)$ & $1.0(0.8-1.2)$ & $1.1(0.9-1.3)$ & $1.2(0.9-1.5)$ & $1.2(0.9-1.6)$ \\
\hline No siblings & Ref. & Ref. & Ref. & Ref. & Ref. & Ref. \\
\hline Siblings & $1.1(0.8-1.6)$ & $1.2(0.8-1.6)$ & $1.0(0.8-1.4)$ & $1.1(0.8-1.4)$ & $0.9(0.6-1.3)$ & $1.0(0.6-1.4)$ \\
\hline \multicolumn{7}{|l|}{ Maternal education } \\
\hline$<12$ years & $1.2(0.9-1.5)$ & $1.1(0.8-1.4)$ & $1.1(0.9-1.3)$ & $0.9(0.7-1.1)$ & $1.0(0.8-1.4)$ & $0.9(0.6-1.2)$ \\
\hline $12-15$ years & $1.1(0.9-1.5)$ & $1.1(0.9-1.5)$ & $1.1(0.9-1.3)$ & $0.9(0.7-1.1)$ & $1.0(0.8-1.4)$ & $0.9(0.6-1.3)$ \\
\hline$<15$ years & Ref. & Ref. & Ref. & Ref. & Ref. & Ref. \\
\hline \multicolumn{7}{|l|}{ Parental ethnicity } \\
\hline Caucasian & Ref. & Ref. & Ref. & Ref. & Ref. & Ref. \\
\hline African & $1.4(1.0-2.1)$ & $1.5(1.0-2.2)$ & $1.7(1.2-2.3)$ & $1.7(1.2-2.3)$ & $1.7(1.1-2.6)$ & $1.6(1.0-2.6)$ \\
\hline Asian & $1.2(0.9-1.6)$ & $1.2(0.9-1.7)$ & $1.5(1.2-1.9)$ & $1.6(1.2-2.0)$ & $1.2(0.9-1.0)$ & $1.2(0.8-1.8)$ \\
\hline
\end{tabular}

Results expressed as crude (cOR) and adjusted odds ratios (aOR) with $95 \%$ confidence intervals in parentheses.

The risk factors gender, child atopy, dampness, smoking, siblings, maternal education, parental ethnicity, and siblings were included in multivariate logistic regression analysis in order to control for potential confounding effects. 


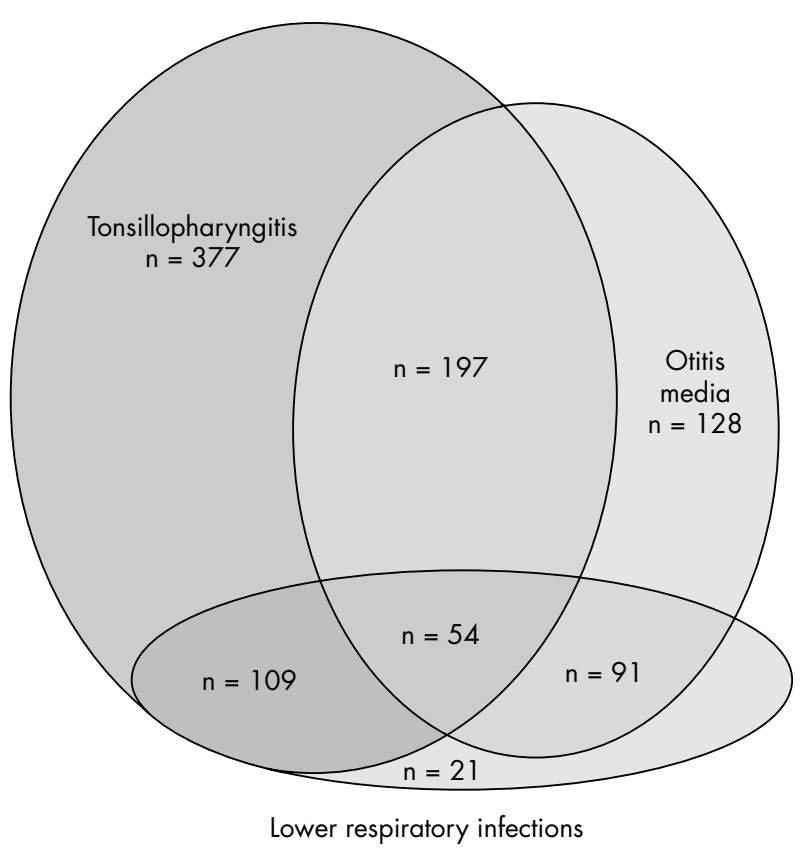

Figure 1 Distribution of infectious co-morbidity in the Oslo Birth Cohort of 10 year old children $(n=3406)$.

Corresponding figures for tonsillopharyngitis and lower respiratory infections were $21.6 \%(n=737)$ and $8.1 \%$ $(n=275)$. A small proportion of the children had experienced more than two episodes of infectious disease in the past year: $4.1 \%$ otitis media, $7.3 \%$ tonsillopharyngitis, and $2.6 \%$ lower respiratory infections. More than half, 56.5\% ( $\mathrm{n}=1924)$, experienced none of the measured infections in the past year.

The distributions of the environmental and constitutional risk factors are listed in Table 1. The children not affected by the infections showed small differences in their characteristics in comparison to the children with airway infections.

Missing responses to the survey questions were as follows: atopic disease in child, $\mathrm{n}=30$; siblings, $\mathrm{n}=61$; smoking by care-giver, $\mathrm{n}=60$; home dampness, $\mathrm{n}=60$; maternal education, $\mathrm{n}=62$; ethnic group, $\mathrm{n}=62$. Gender and parental atopic disease had no missing values.

Risk factors for the respiratory infections are listed in table 2. Dampness in the home was a risk factor for all infections, adjusted odds ratios ranging from 1.2 (95\% CI 1.0 to 1.5$)$ for otitis media to 1.4 (95\% CI 1.1 to 1.6$)$ for tonsillopharyngitis. In the merged variable of home dampness, water leakage in the home was consistently a risk for all infections, crude odds ratios ranging from 1.6 (95\% CI 1.1 to $2.2)$ to $1.7(95 \%$ CI 1.1 to 2.7$)$. The other, separate constituents of home dampness-signs of mould, dew on windows during winter, and spots of moisture on walls or ceiling-also gave coherent effects, but these were not statistically significant, crude odds ratios ranging from 1.1 (95\% CI 0.7 to 1.8 ) to 1.6 (95\% CI 0.8 to 3.3 ) for otitis media, $1.3(95 \%$ CI 0.8 to 1.9$)$ to 1.9 (95\% CI 1.0 to 3.0$)$ for tonsillopharyngitis, and 1.1 (95\% CI 0.6 to 2.1 ) to 1.9 (95\% CI 0.8 to 4.4 ) for lower respiratory infections. Female gender increased the probability of otitis media and tonsillopharyngitis, adjusted odds ratios ranging from 1.2 (95\% CI 1.0 to 1.4) to 1.2 (95\% CI 1.0 to 1.5$)$. Child atopy increased the risk for all infections, particularly for lower airway infections (adjusted odds ratio $2.4,95 \%$ CI 1.8 to 3.1 ). Home dampness was not associated with reports of atopic disease (adjusted odds ratio $1.0,95 \%$ CI 0.8 to 1.2 ). Smoking by a care-provider did not influence the occurrence of infections significantly.
Having a parent from African or Asian countries was a determinant for the airway infections (table 2).

The co-morbidity between otitis media, tonsillopharyngitis, and lower respiratory infections is illustrated in fig 1 . Significant associations were found between all airway infections, crude and adjusted odds ratios ranging two to threefold (table 3 ).

Adjusted odds ratios controlled for gender, atopy, and maternal education

\section{DISCUSSION}

Otitis media, tonsillitis, and lower respiratory infections were common in 10 year old children. Home dampness, atopy, and ethnicity were significant determinants of the respiratory infections, while smoking by care-provider did not significantly increase risk of infection. A substantial infectious comorbidity was confirmed.

Some limitations of our study need to be addressed. The disease occurrence was based on parental report which may have generated misclassification and recall bias. However, symptoms of ear and throat infection are distinct in the studied age group and systematic exaggerated reporting is not likely. The questionnaire was originally designed for the study of atopic disease and therefore misclassification of infectious disease reports seems unlikely. The cross-sectional design confined us to study temporal and not causal associations. Having considered the above reservations we concluded that our data were reliable and would enable us to fulfil our research aims.

de $\mathrm{Ru}$ and Grote have proposed that the viscous type of otitis media is a protective reaction to an infectious disease in a child and that the condition will resolve once the immune system and Eustachian tube function are mature. ${ }^{14}$ Contrary to this view, we found ear infections in $13.8 \%$ of the schoolchildren. In a comparable group of Norwegian 4 year olds, only $9.5 \%$ reported otitis media. ${ }^{12}$ Yet other studies have reported otitis media, myringotomy, and ventilation tube insertions mainly to occur in preschool children. ${ }^{15}$ We suggest that our high prevalence of otitis media in 10 year olds should be further explored as this may alter some of the defined causal paths for the condition. ${ }^{16}$ Gender predominance of otitis media has not been reported in preschool children. ${ }^{17}$ Our study is, as far as we know, the first population based study of schoolchildren; we found girls to be more prone to otitis media and tonsillopharyngitis. This may be due to age specific differences in the occurrence of infections, but our study design does not allow us to conclude on the latter finding; more population based studies of this age group are needed. In contrast to otitis media, clinical studies have suggested that tonsillitis cannot be regarded as a natural part of the immune maturation process as it has a low rate of spontaneous recovery. ${ }^{18} 19$ The present study confirmed a high prevalence of tonsillopharyngitis in schoolchildren. The finding is in accordance with the age specific prevalence reported in a clinical sample in Finland. ${ }^{6}$ We believe that the present study is one of the first population based prevalence estimates of tonsillopharyngitis, confirming clinical experience and requesting further studies.

Our study did not find an effect of maternal education on the prevalence of infections. Rather, a consistent relation between infections and ethnicity was evident. Previous studies of the association between otitis media and ethnicity have questioned the ability to differentiate between constitutional and environmental factors, including socioeconomic factors in African Americans, Aborigines, and Inuits. ${ }^{20-22}$ In our study, children with one or both parents from African and Asian countries had increased probability for otitis media, tonsillopharyngitis, and lower respiratory tract infections compared to children with one or both Caucasian 


\section{What is already known on this topic}

- Occurrence and risk factors for otitis media in toddlers and preschool children

- Co-morbidity between upper airway infections

parents. The ethnic variable is representative for Africans and Asians as it is based on nationality rather than ethnic belonging. The ethnic differences are probably multi-layered; Africans and Asians are minority groups in Norway and it cannot be concluded whether the variance is due to constitutional differences, aberrant living conditions, or differences in reporting within the minority groups. Cultural and linguistic differences may have lead to selection of responders within the minority groups, thus limiting the interpretations of our results.

Smoking by a care-provider was not significantly associated with the respiratory infections, thus corroborating earlier studies in children of school age. ${ }^{23}$ Low exposure levels may explain the finding since 10 year olds are in less close contact with their care providers compared to children in younger age groups. However, increased awareness of the adverse health effects of passive smoking may be another explanation for the lack of association.

Many studies have found evidence for a causal relationship between dampness in buildings and a number of health effects, in particular asthma. ${ }^{24}$ The relation between dampness and respiratory infections has been less well explored. ${ }^{26-29}$ In our study we found indicators of home dampness to be positively associated with both upper and lower airway infections. Our results may be viewed in the light of a report of pro-inflammatory cytokines. ${ }^{30}$ TNF- $\alpha$ and IL-1 found in nasal lavage and induced sputum in workers exposed to a water damaged building suggested similar host defence mechanisms for both upper and lower airways. While dampness and atopy were both determinants for airway infections in our study population, dampness did not increase the probability of atopic disease. The latter may suggest that the effect of dampness on atopic disease is mediated by increased probability of respiratory infections.

In a subgroup of children more prone to infections, we found considerable co-morbidity between otitis media, tonsillopharyngitis, and lower respiratory infections (table 3). There was a two- to threefold risk of another respiratory infection following previous episodes. Our finding is in accordance with earlier reports of significant comorbidity between otitis media, tonsillopharyngitis, and the common cold. ${ }^{10}{ }^{11}$ Lower respiratory tract infections were not included in the latter studies. We found otitis media associated with both tonsillopharyngitis and lower respiratory infection, thus indicating a close relationship between upper and lower airways; a shared infectious tendency. Shared immunological mechanisms was explored by Brandtzaeg and reported as a common distribution of

\section{What this study adds}

- Occurrence and risk factors for otitis media and other respiratory infections in schoolchildren

- Co-morbidity between upper and lower airway infections

antibodies in the respiratory tract, enhancing the importance of the organs of the Waldeyer ring for the immunocompetence of lower airways as well. ${ }^{31}$ The report by Purokivi et al on common host defence mechanisms also contributes to the concept of united airways. ${ }^{30}$ Clinically, the unity of upper and lower airways may be related to common environmental and constitutional factors which are not explored further in this paper.

\section{Conclusions}

We found respiratory tract infections common in 10 year old children. Home dampness, atopic disease, and ethnicity were determinants for all infections along with substantial comorbidity between upper and lower airway infections. Our findings support the hypothesis of 1957 that the whole respiratory tract is one unit. ${ }^{3}$

\section{Authors' affiliations}

G Karevold, Faculty Division of Akershus University Hospital, University of Oslo, Norway

E Kvestad, Division of Epidemiology, Norwegian Institute of Public Health, Oslo, Norway

P Nafstad, Department of General Practice and Community Medicine, University of Oslo, Norway

K J Kværner, Department of Otorhinolaryngology, Akershus University Hospital, Oslo, Norway

Competing interests: none declared

\section{REFERENCES}

1 Cunha BA. Therapeutic implications of antibacterial resistance in communityacquired respiratory tract infections in children. Infection 2004;32:98-108.

2 Claeys S, de Belder T, Holtappels G, et al. Human beta-defensins and toll-like receptors in the upper airway. Allergy 2003:58:748-53.

3 MRC. Acute otitis media in general practice; report of a survey by the Medical Research Council's Working-Party for Research in General Practice. Lancet 1957;273:510-14

4 Dewey C, Midgeley E, Maw R. The relationship between otitis media with effusion and contact with other children in a British cohort studied from 8 months to $3 \frac{1}{2}$ years. The ALSPAC Study Team. Avon Longitudinal Study of Pregnancy and Childhood. Int J Pediatr Otorhinolaryngol 2000;55:33-45.

5 Teele DW, Klein JO, Rosner B. Epidemiology of otitis media during the first seven years of life in children in greater Boston: a prospective, cohort study 122. J Infect Dis 1989;160:83-94.

6 Mattila PS, Tahkokallio O, Tarkkanen J, et al. Causes of tonsillar disease and frequency of tonsillectomy operations. Arch Otolaryngol Head Neck Surg 2001; 127:37-44

7 Syrogiannopoulos GA, Bozdogan B, Grivea IN, et al. Two dosages of clarithromycin for five days, amoxicillin/clavulanate for five days or penicillin $\checkmark$ for ten days in acute group A streptococcal tonsillopharyngitis. Pediatr Infect Dis J 2004;23:857-65.

Table 3 Estimated crude odds ratios (cOR) and adjusted odds ratios (aOR) between otitis media, tonsillopharyngitis, and lower respiratory infections in the Oslo Birth Cohort of 10 year old children $(n=3406)$

\begin{tabular}{|c|c|c|c|c|c|c|}
\hline & \multicolumn{2}{|l|}{ Otitis media } & \multicolumn{2}{|c|}{ Tonsillopharyngitis } & \multicolumn{2}{|c|}{ Lower respiratory infection } \\
\hline & COR & aOR & COR & aOR & COR & aOR \\
\hline $\begin{array}{l}\text { Otitis media } \\
\text { Tonsillopharyngitis } \\
\text { Lower respiratory infection }\end{array}$ & $\begin{array}{l}\text { Ref. } \\
3.1(2.6-3.9) \\
3.5(2.7-4.6)\end{array}$ & $\begin{array}{l}\text { Ref. } \\
2.8(2.3-3.5) \\
2.9(2.1-3.8)\end{array}$ & $\begin{array}{l}\text { Ref. } \\
2.6(2.0-3.3)\end{array}$ & $\begin{array}{l}\text { Ref. } \\
2.3(1.3-1.9)\end{array}$ & Ref. & Ref. \\
\hline
\end{tabular}


8 Brook I, Gober AE. Treatment of non-streptococcal tonsillitis with metronidazole. Int J Pediatr Otorhinolaryngol 2005;69:65-8.

9 Maltezou HC, La-Scola B, Astra H, et al. Mycoplasma pneumoniae and Legionella pneumophila in community-acquired lower respiratory tract infections among hospitalized children: diagnosis by real time PCR. Scand J Infect Dis 2004;36:639-42.

10 Schilder AG, Zielhuis GA, Straatman HS, et al. An epidemiological approach to the etiology of middle ear disease in The Netherlands. Eur Arch Otorhinolaryngol 1992:249:370-3.

11 Kvaerner KJ, Tambs K, Harris JR, et al. Otitis media: relationship to tonsillitis, sinusitis and atopic diseases. Int J Pediatr Otorhinolaryngol 1996;35:127-41.

12 Kvaerner KJ, Nafstad P, Jaakkola JJ. Upper respiratory morbidity in preschool children: a cross-sectional study. Arch Otolaryngol Head Neck Surg 2000;126:1201-6

13 Norwegian Institute of Public Health. Report from Oslo Birth Cohort. Norwegian Institute of Public Health, 1997.

14 de Ru JA, Grote JJ. Otitis media with effusion: disease or defense? A review of the literature. Int J Pediatr Otorhinolaryngol 2004;68:331-9.

15 Desai SN, Kellner JD, Drummond D. Population-based, age-specific myringotomy with tympanostomy tube insertion rates in Calgary, Canada. Pediatr Infect Dis J 2002;21:348-50.

16 Rovers MM, Schilder AG, Zielhuis GA, et al. Otitis media. Lancet 2004:363:465-73.

17 Midgley EJ, Dewey C, Pryce K, et al. The frequency of otitis media with effusion in British pre-school children: a guide for treatment. ALSPAC Study Team. Clin Otolaryngol Allied Sci 2000;25:485-91.

18 Woolford TJ, Ahmed A, Willatt DJ, et al. Spontaneous resolution of tonsillitis in children on the waiting list for tonsillectomy. Clin Otolaryngol 2000;25:428-30.

19 Prim MP, de Diego Jl, Larrauri M, et al. Spontaneous resolution of recurrent tonsillitis in pediatric patients on the surgical waiting list. Int $J$ Pediatr Otorhinolaryngol 2002;65:35-8.

20 Vernacchio L, Lesko SM, Vezina RM, et al. Racial/ethnic disparities in the diagnosis of otitis media in infancy. Int J Pediatr Otorhinolaryngol 2004;68:795-804
21 Coates HL, Morris PS, Leach AJ, et al. Otitis media in Aboriginal children: tackling a major health problem. Med J Aust 2002; 177:177-8.

22 Homoe P, Lynnerup N, Skovgaard LT, et al. Estimation of otitis media in ancient populations. A study of past and present Greenlandic Inuit. J Laryngol Otol 1996;110:1114-19.

23 Cook DG, Strachan DP. Health effects of passive smoking. 10: Summary of effects of parental smoking on the respiratory health of children and implications for research. Thorax 1999;54:357-66.

24 Mendell MJ, Heath GA. Do indoor pollutants and thermal conditions in schools influence student performance? A critical review of the literature. Indoor Air 2005;15:27-52.

25 Bornehag CG, Blomquist G, Gyntelberg F, et al. Dampness in buildings and health. Nordic interdisciplinary review of the scientific evidence on associations between exposure to "dampness" in buildings and health effects (NORDDAMP). Indoor Air 2001;11:72-86.

26 Spengler JD, Jaakkola JJK, Parise H, et al. Housing characteristics and children's respiratory health in the Russian Federation. Am J Public Health 2004; $94: 657-62$

27 Taskinen T, Hyvarinen A, Meklin T, et al. Asthma and respiratory infections in school children with special reference to moisture and mold problems in the school. Acta Paediatr 1999;88:1373-9.

28 Kilpelainen $\mathbf{M}$, Terho EO, Helenius $\mathrm{H}$, et al. Home dampness, current allergic diseases, and respiratory infections among young adults. Thorax 2001;56:462-7.

29 Koskinen OM, Husman TM, Meklin TM, et al. The relationship between moisture or mould observations in houses and the state of health of their occupants. Eur Respir J 1999;14:1363-7.

30 Purokivi MK, Hirvonen MR, Randell JT, et al. Changes in pro-inflammatory cytokines in association with exposure to moisture-damaged building microbes. Eur Respir J 2001;18:951-8.

31 Brandtzaeg P. Immunology of tonsils and adenoids: everything the ENT surgeon needs to know. Int J Pediatr Otorhinolaryngol 2003;67/suppl 1):S69-76.

\section{ARCHIVIST}

\section{Iron and folic acid in Zanzibar and Nepal}

$\mathrm{T}$ he findings of the World Health Organization's Global Burden of Disease project indicated that underweight and micronutrient deficiencies were the main factors underlying child deaths in developing countries. Supplementation with vitamin A, iron, folate, and zinc is widely recommended but there is controversy, particularly about the routine use of iron and folic acid; it is feared that extra iron might favour the growth of bacterial pathogens and malaria parasites. Studies in Zanzibar and Nepal have been reported in a single issue of The Lancet (Sunil Sazawal and colleagues. Lancet 2006;367:133-43; James M Tielsch and colleagues. Ibid: 144-52; see also Comment, ibid: 90-1).

The two trials were parallel studies conceived in Baltimore. In each trial children more than 1 month and less than 3 years old were randomised to one of four options: iron and folic acid; iron, folic acid, and zinc; placebo; or zinc alone. All children received vitamin A (apart from children under 6 months old in Nepal). The trials stopped early for the groups taking iron and folic acid and results are reported for only the first three of the four groups. At each site each of these groups contained some 8000-9000 children.

In Zanzibar, among children taking iron and folic acid with or without zinc, the rate of all serious adverse events (deaths and admissions to hospital) was increased significantly by $12 \%$ compared with the placebo group. There was a non-significant $15 \%$ increase in mortality. The first two groups also had significantly more morbidity and mortality from malaria and other infections compared with the placebo group.

In Nepal, where there is little risk of malaria, there was no significant difference in mortality between the first two groups and the placebo group. There were non-significant reductions in diarrhoea, dysentery, and acute respiratory illnesses.

In areas of developing countries where malaria is endemic universal administration of iron and folic acid may be harmful. Such treatment should be restricted to anaemic children and case management of severe illnesses needs to be strengthened. Where there is little risk of malaria routine supplementation with iron and folic acid does no harm and may be beneficial. 